\title{
Left-Handedness and Artistic Abilities: A First Look
}

Sangeeta Singg ${ }^{*}$ and Zane Martin

Department of Psychology, Angelo State University, USA

*Corresponding author: Sangeeta Singg, Professor of Psychology, Angelo State University, San Angelo, Texas 76909, USA, Tel: 1-325-223-8606; Fax: 1-325-942-2290; E-mail: sangeeta.singg@angelo.edu

Received date: December 29, 2015; Accepted date: January 22, 2016; Published date: January 25, 2016

Copyright: (c) 2016 Singg S, et al. This is an open-access article distributed under the terms of the Creative Commons Attribution License, which permits unrestricted use, distribution, and reproduction in any medium, provided the original author and source are credited.

\begin{abstract}
A sample of healthy18 undergraduate college women (9 left-handers and 9 right-handers) without any learning disabilities enrolled at a regional southwestern university in the United States signed an informed consent form, and were administered a general information questionnaire and the Artistic Abilities subscale of "Competencies" subsection of the Holland's Self-Directed Search, Form R. They also signed an informed consent form. Because of the conflicting findings in research on handedness and on artistic abilities, the variable of sex was held constant in this study. Thus, left- and right-handed women were compared on the following variables: prevalence of lefthandedness in the family, academic performance, and artistic abilities. Significant differences were found between left- and right- handers on all variables except academic performance. Following conclusions were made on the basis of the results of this preliminary study: (1) left-handers tend to be more artistic than the right-handers and (2) heredity is one of the several determinants of handedness. Expectancy effect, brain lateralization, and functional theory were suggested as possible explanations for the link between left-handedness and artistic abilities.
\end{abstract}

Keywords: Left-handers; Handedness; Non-right-handedness; Sinistrality; Artistic abilities

\section{Introduction}

We live in a right-handed world where left-handers are frequently reminded of their handedness as an oddity. Also known as Sinistrality (derived from the Latin word sinister meaning "left" as well as "unlucky") the issue of left-handedness has been studied theoretically and empirically for over a century without any definite resolution. About $90 \%$ of the human population is right-handed with minor geographical variations due to cultural pressure against lefthandedness, and the right-handedness predominance has persisted throughout human history [1]. The left-handers are those who tend to use left hand for writing, tool use, sports, and activities of daily living. The prevalence of left-handedness is slightly higher in males than in females. Also, research has confirmed that handedness is not a discrete variable including two categories of right- or left-handers. Instead it is a continuous variable occurring at levels between strong left- and strong right-handedness [2-5].

Human left-handedness has generated much research with some intriguing findings indicating a possible link between left-handedness and various physical, psychological, and performance variables. Some have tried using left-handedness as a predictor of some psychological and physical problems. It is also used as a marker for brain lateralization. A brief summary of some pertinent findings is presented below.

Left-handedness tends to be more prevalent in patients with schizophrenia and brain laterality is believed to play the role in this connection [6]. Also greater incidence of left-handedness coexists with autism [7], borderline personality disorder [8], and mental retardation [9]. Much higher mortality rate has been found to exist among the lefthanders than the right-handers [10]. Left-handedness is also associated with several chronic diseases such as cardiac autonomic functions [11], migraine headaches [12], dyslexia [13], bronchial asthma [14], and diabetes mellitus [15].

Not all findings in left-handedness research are gloomy. There are some positive findings as well. For example, higher IQ has been associated with left-handedness. Many great geniuses in the history have been left-handers [16] and four of the last seven US presidents (Gerald Ford, George H. W. Bush, Bill Clinton, and Barack Obama) were also left-handers [17]. In interactive sports such as table tennis, badminton, cricket, and tennis, left-handers have excelled and may have an advantage over right-handers; maybe because they are better than right-handers at some visuomotor tasks [18]. The incidence of left-handedness has also been found to be very high in some professions and some educational fields, for example arts and music $[19,20]$. There is also a lengthy list of names of famous left-handed artists such as Leonardo da Vinci, Pablo Picasso, Michelangelo Buonarroti, Albrecht Dürer, Rembrandt van Rijn, Peter Paul Rubens, and Paul Klee, but there is limited empirical research indicating that left-handedness is linked to artistic ability. We came across one study that investigated this connection. A study of 1,045 undergraduate students found that more left-handed students in the United States majored in music and visual arts than in the sciences [19]. Because of this paucity in research, the present preliminary study examined the relationship between left-handedness and artistic abilities.

We do not have a definite answer for what causes left-handedness, but there are several theories about the development of human handedness. Different researchers have argued in favor of different explanations. Hand preference as a heritable trait is a widely accepted explanation with a current conclusion that handedness is polygenic $[21,22]$; heritability estimates range from 0.23 to 0.66 [23]. Another popular one is the brain lateralization explanation which is based on the hemispheric functional specializations. In most people, righthandedness predominates and the left hemisphere controls speaking which is believed to be reversed in left-handers. The brains of the lefthanders are organized with reversed hemispheres or both hemispheres 
are used for verbal processing, and the brain-division of labor is less lateralized. The right hemisphere deals with perceptions of environment, music, art, geometry, and esthetics [24]. Other explanations of the determinism of hand preference are from developmental [25], cultural [26], and functional [27] perspectives. A newer model called "functional theory of human handedness" has been proposed with assumption that left-handedness is a symbolic aid to cope creatively with early childhood conflicts [27]. However, most researchers have focused on genetic factors and early childhood development which have led to the nature versus nurture controversy $[28,29]$.

There are conflicting research findings with regard to sex differences in relation to left-handedness. However, the conclusion of a metaanalysis of 144 studies is that left-handedness is slightly more prevalent among men as compared to women [4]. Some studies have used sex as an independent variable to rule out its intervening effect on handedness. However, many studies have not taken the sex variable into consideration which might be one of the reasons for conflicting findings in the handedness research. For example, a study examining the relationship between handedness and divergent thinking found a significant relation between divergent thinking and handedness in males (left-handed males had higher divergent scores), but not in in females [30]. This finding would have been obscured if the researcher did not use sex as an independent variable.

There are also conflicting findings about the relationship between sex and artistic abilities [31,32]. A conclusion of a 2009 meta-analysis of sex differences in interests was that generally more women tend to indicate interest in artistic activities than do men [33]. Thus, in order to improve the internal validity of the present study, the variable of sex was held constant since research on both handedness and artistic abilities had yielded conflicting results. Also, along with artistic abilities, we extended our investigation to include variables of prevalence of left-handedness in the family and academic success (measured as Grade Point Average; GPA). However, the main hypothesis of the present study was that left-handed women would be significantly more artistic than the right-handed women.

\section{Method}

Eighteen undergraduate female students (14 Caucasians and 4 Hispanics; ages 18-26 years, $\mathrm{M}=20, \mathrm{SD}=1.81$ ) enrolled at a southwestern regional university in the United States were selected out of a psychology classes sample pool of 289 students for the present study. All participants signed an informed consent form. Of the 18 females, 9 strong left-handers were matched with 9 strong righthanders. They were selected on the basis of their response as "No" on a screening test about any physical/learning disabilities and responses indicating strong left or right handedness to a question about the following activities: (1) writing, (2) throwing a ball, (3) brushing teeth, and (4) eating with a spoon. If they responded "always left or right" for all four activities or "always left or right" for three of the four activities plus "usually left or right" for one activity, they were considered strong left-handers or strong right-handers. Five possible responses were "always left," "usually left," "both equally," "usually right" or "always right." After obtaining 9 strong left-handed women, 9 strong righthanded women were matched by age and ethnic background. All 18 women completed a general information questionnaire and the Artistic Ability (A) subscale of "Competencies" subsection of the Self-Directed Search (SDS), Form R [34]. The SDS is an interest inventory that assesses a person's personality type measured by the following scales:
Realistic, Investigative, Artistic, Social, Enterprising, and Conventional. Internal consistency coefficients for these scales range from .90 to .94 and test-retest reliability coefficients range from .76 to . 89. The Artistic Ability subscale of the "Competencies" subsection consists of 11 items responded as "Yes" or "No." The scores range from $0-11$. Artistic types tend to have artistic skills, enjoy creating original work and have good imaginations. They like artistic careers such as composer, musician, stage director, dancer, interior decorator, actor, and writer. The Artistic types are also described as complicated, disorderly, emotional, expressive, idealistic, imaginative, impractical, impulsive, independent, introspective, intuitive, nonconforming, open, and original [35].

\section{Results}

Significantly greater number (44\%) of left-handed women reported having one or more left-handed immediate family members than did the right-handed women (12\%), a difference that was not statistically significant $(\mathrm{P}=0.294$, Fisher's exact test). Although the results were not significant, left-handed women had higher mean GPA (3.29, $\mathrm{SD}=0.43$ ) than the right-handed women $(\mathrm{M}=3.15, \mathrm{SD}=0.48 ; \mathrm{t}=1.26(16), \mathrm{p}>0.05)$. A significant difference was observed between left- and right-handed women with regard to their mean Artistic Competencies scores $(\mathrm{t}=2.15(16), \mathrm{p}<0.05)$. The mean Artistic Competencies score $(\mathrm{M}=6.44$, $\mathrm{SD}=2.13$ ) of left-handed women was significantly greater than the mean Artistic Competencies score $(\mathrm{M}=4.43, \mathrm{SD}=1.81)$ of right-handed women.

\section{Discussion}

The results of the present study indicated that left-handers are more likely to have other family members with left-handedness than the right-handers. However, because $56 \%$ of the left-handers did not report having any family members with left-handedness, the assumption that the left-handedness is hereditary is not fully supported. Instead, this finding is consistent with the assumption that handedness is a multifactor characteristic involving more than just genetic etiology. Although the results were not significant, the lefthanders had a higher mean GPA than the right-handers which is an important observation for a small sample of women and is consistent with the assumption that the left-handers tend to be high achievers [36].

The results supported the main hypothesis of the present study. It was concluded that left-handers tend to show significantly more artistic competencies than the right-handers. There could be several possible explanations for this finding; three explanations are offered here. One reason for left-handers reporting having more artistic abilities might be that they live up to the well-publicized expectation (expectancy effect) that left-handers tend to be more artistic and famous artists' names are associated with this expectation. Parents, teachers, and others may reinforce this expectation at an early age with a left-hander, especially when a child experiences difficulties in a righthanded world.

While it is beyond the scope of this article to explicate the underlying mechanisms of the brain of artistic individuals, suggestions are rendered regarding brain lateralization as another possible explanation for the link between left-handedness and artistic abilities. The neurodevelopmental theory of right and left hemisphere dominance states that right side is the creative and artistic side as opposed to left side which uses logic and reason. Thus, you would 
expect a left-hander who is dominated by the right side of the brain to be artistic. Also, left-handed persons might be more visual than language-based which makes them more prone to pursue artistic interests as was shown in the study of university students [19].

Yet another possible explanation is the functional theory of human handedness [27]. It assumes that imitation and social learning are two major factors involved in the development of handedness in early childhood. The link between left-handedness and artistic abilities may be understood by taking into account the function or meaning of lefthandedness for personality development. Left-handedness is a "ubiquitous symbolic aid" for coping creatively with early childhood psychological conflicts due to frustrations of being left-handed in a right-handed world [27].

Two conclusions of the present preliminary study are (1) lefthanders tend to be more artistic than the right-handers and (2) heredity is one of the several determinants of handedness. At the present time, it remains a matter of speculation as to why left-handers tend to be more artistic than the right-handers. There is much to be explored by the future research to fully understand the underlying mechanisms of the complex link between left-handedness and artistic abilities. The present preliminary study has made an attempt to stimulate some questions and possibilities. The results of this "first look" attempt indicate that further research on the link between lefthandedness and artistic abilities with larger samples and additional controls is warranted.

\section{References}

1. Perelle IB, Ehrman L (2005) On the other hand. Behav Genet 35: 343-350.

2. Peters M, Pedersen K (1978) Incidence of left-handers with inverted writing position in a population of 5910 elementary school children. Neuropsychologia 16: 743-746.

3. Grimshaw GM, Wilson MS (2013) A sinister plot? Facts, beliefs, and stereotypes about the left-handed personality. Laterality 18: 135-151.

4. Papadatou-Pastou M, Martin M, Munafò MR, Jones GV (2008) Sex differences in left-handedness: a meta-analysis of 144 studies. Psychol Bull 134: 677-699.

5. Raymond M, Pontier D, Dufour AB, Møller AP (1996) Frequencydependent maintenance of left handedness in humans. Proc Biol Sci 263: 1627-1633.

6. Sommer I, Ramsey N, Kahn R, Aleman A, Bouma A (2001) Handedness, language lateralisation and anatomical asymmetry in schizophrenia: meta-analysis. Br J Psychiatry 178: 344-351.

7. Dane S, Balci N (2007) Handedness, eyedness and nasal cycle in children with autism. Int J Dev Neurosci 25: 223-226.

8. Niederhofer H (2004) Left-handedness in a sample of nine patients with borderline personality disorder. Percept Mot Skills 99: 849-852.

9. Mandal MK, Pandey G, Das CT, Bryden MP (1998) Handedness in mental retardation. Laterality 3: 221-225

10. Coren S, Halpern DF (1991) Left-handedness: a marker for decreased survival fitness. Psychol Bull 109: 90-106.

11. Krommydas G, Gourgoulianis KI, Andreou G, Molyvdas PA (2003) Lefthandedness in asthmatic children. Pediatr Allergy Immunol 14: 234-237.

12. Waldie KE, Hausmann M, Milne BJ, Poulton R (2002) Migraine and cognitive function: a life-course study. Neurology 59: 904-908.
13. Tønnessen FE, Løkken A, Høien T, Lundberg I (1993) Dyslexia, lefthandedness, and immune disorders. Arch Neurol 50: 411-416.

14. Searleman A, Fugagli AK (1987) Suspected autoimmune disorders and left-handedness: evidence from individuals with diabetes. Crohn's disease and ulcerative colitis. Neuropsychologia 25: 367-374.

15. Voulgari C, Moyssakis I, Perrea D, Kyriaki D, Katsilambros N, et al. (2010) The association between the spatial QRS-T angle with cardiac autonomic neuropathy in subjects with Type 2 diabetes mellitus. Diabet Med 27: 1420-1429.

16. Porac C, Coren S (1981) Lateral preferences and human behavior (1stedn), Springer-Verlag, New York.

17. Kerns K (2015) What Being Left-Handed Says About Your Personality. Huffpost Healthy Living.

18. Holtzen DW (2000) Handedness and professional tennis. Int J Neurosci 105: 101-119.

19. Peterson JM (1979) Left-handedness: differences between student artists and scientists. Percept Mot Skills 48: 961-962.

20. Mebert CJ, Michel GF (1980) Handedness in artists: Neuropsychology of left-handedness. Academic Press, New York.

21. Sicotte NL, Woods RP, Mazziotta JC (1999) Handedness in twins: a metaanalysis. Laterality 4: 265-286.

22. McManus IC, Davison A, Armour JAL (2013) Multi-locus genetic models of handedness closely resemble single-locus models in explaining family data and are compatible with genome-wide association studies. Ann N Y Acad Sci 1288: 48-58.

23. Saudino K, McManus IC (1998) Handedness, footedness, eyedness and earedness in the Colorado Adoption Project. Br J Dev Psychol 16: 167-174.

24. Banich M (1997) Neuropsychology: The Neural Bases of Mental Function. Houghton Mifflin, Boston.

25. Yeo RA, Gangestad SW (1993) Developmental origins of variation in human preference. Genetica 89: 281-296.

26. Fagard J, Dahmen R (2004) Cultural influences on the development of lateral preferences: a comparison between French and Tunisian children. Laterality 9: 67-78.

27. JanBen JP (2004) Foundations of a functional theory of human handedness. Theory and Psychology 10: 357-398.

28. Corballis MC (1997) The genetics and evolution of handedness. Psychol Rev 104: 714-727.

29. Yeo RA, Gangstad SW, Daniel WF (1993) Hand preference and developmental instability. Psychobiology 21: 161-168.

30. Coren S (1995) Differences in divergent thinking as a function of handedness and sex. Am J Psychol 108: 311-325.

31. Betz NE, Fitzgerald LF (1987) The career psychology of women. Orlando, FL: Academic Press.

32. Charyton C, Snelbecker GE (2007) General, artistic and scientific creativity attributes of engineering and music students. Creativity Research Journal 19: 213-225.

33. Su R, Rounds J, Armstrong PI (2009) Men and things, women and people: a meta-analysis of sex differences in interests. Psychol Bull 135: 859-884.

34. Holland JL, Fritzsche B, Powell A (1994) The self-directed search: Technical manual. Psychological Assessment Resources, Odessa, FL.

35. Holland JL (1997) Making vocational choices: A theory of vocational personalities and work environments. (3rdedn), Psychological Assessment Resources, Odessa, FL.

36. McManus IC (2012) Is It True That Left-Handed People Are Smarter Than Right-Handed People? Scientific American. 